\title{
Predicting academic success in higher education: what's more important than being smart?
}

\author{
Rutger Kappe $\cdot$ Henk van der Flier
}

Received: 22 November 2010 /Revised: 10 November 2011 /Accepted: 28 December 2011 /

Published online: 1 February 2012

C) The Author(s) 2012. This article is published with open access at Springerlink.com

\begin{abstract}
This study investigated the combined predictive validity of intelligence and personality factors on multiple measures of academic achievement. Students in a college of higher education in the Netherlands $(N=137)$ completed a survey that measured intelligence, the Big Five personality traits, motivation, and four specific personality traits. Student performance was measured with grade point average (GPA) and time to graduation, as well as with five specific performance measures: regular exams, skills training, team projects, internships, and a written thesis. Results show that $33 \%$ of the variance in GPA and $30 \%$ of the variance in time to graduation can be explained by combining intelligence, personality, and motivational predictors. Conscientiousness is the best predictor across a broad spectrum of academic achievement measures and explains five times as much variance in GPA as does intelligence. The practical implications are that institutes of higher education should collect personality data on students at the outset and then help students accordingly. Highly conscientious students who are organized and internally motivated might potentially be offered more challenging honours programs with corresponding special commendations on their diplomas, whereas students who score low on conscientious would receive more structure through student study groups, frequent deadlines, shorter assignments, group assignments, clearly defined learning goals, and less second chances for passing examinations.
\end{abstract}

Keywords Academic success $\cdot$ Higher education · Intelligence $\cdot$ Motivation $\cdot$ Personality traits $\cdot$ Predictive validity

Harris (1940) and Cattell (1965) long ago noted the importance of personality factors for predicting academic achievement. Harris (1940) discussed the importance of persistence, in the guise of effort, and concluded that the essential factors for scholastic achievement were:

R. Kappe $(\bowtie) \cdot$ H. van der Flier

Faculty of Psychology and Education, VU University Amsterdam, Van der Boechorststraat 1, 1081

Amsterdam, The Netherlands

e-mail: Rutger.Kappe@inholland.nl

R. Kappe

e-mail: fr.kappe@psy.vu.nl 
(a) ability, otherwise known as intelligence or scholastic aptitude, (b) effort, also known as drive or degree of motivation, and (c) personal, economic, social, and academic circumstances. Years later, Cattell (1965) suggested that, for university students who had already been selected on intelligence, personality and motivation would be just as important for predicting academic achievement. Recent research has shown that personality accounts for variance in academic achievement over and above intelligence (Bratko et al. 2006; Gilles and Bailleux 2001; Noftle and Robins 2007; Poropat 2009), and that personality may have even more predictive power than intelligence at the post-secondary levels of education (Conard 2006; Di Fabio and Busoni 2007; Furnham and Chamorro-Premuzic 2004; Furnham et al. 2003; Petrides et al. 2005).

O'Conner and Paunonen (2007) recently reviewed the studies concerning how well intelligence and personality factors predicted academic achievement at the post-secondary level and reiterated the earlier recommendations of Harris and Cattell. They offered a template for subsequent research and called upon researchers to: (a) use multiple predictors beyond intelligence, such as personality, motivation, and study habits, when predicting academic achievement; (b) use narrow measures of personality, in addition to the Big Five; (c) use multiple and specific measures, in addition to grade point average (GPA), to assess academic achievement; and (d) examine the direct (based on zero-order correlation) predictive utility of each predictor, as well as its incremental validity, in a multivariate context. This paper reports the results of a study with post-secondary students in which the template suggested above was followed. Predictor measures included intelligence, broad and narrow measures of personality, and motivation. Moreover, academic achievement was measured in six different ways in addition to GPA. Finally, multivariate statistics were used to assess the unique and combined effects across the multiple predictors and criteria.

O'Conner and Paunonen (2007) have noted that intelligence has not been a good predictor of academic achievement at the post-secondary education level. This finding has been confirmed in two studies of higher education research in the Netherlands (Busato et al. 2000; Resing and Drenth 2007). Resing and Drenth (2007) reported a modest relationship between academic achievement and intelligence in a general sample of university students, and Busato et al. (2000) reported a minimal correlation of $r=0.13$ in a sample of university psychology students. Based on studies performed in the USA and the UK, ChamorroPremuzic and Furnham (2005) noted that the correlation between intelligence scores and academic achievement decreased as students became older, declining from 0.60 to 0.50 , to 0.40 , and to 0.30 , at the elementary, secondary, university undergraduate, and postgraduate levels, respectively. This decline has often been attributed to 'restriction of range' because students have already been selected on intelligence at each successive stage in their education (Boekaerts 1995). Additional factors, such as personality, are therefore needed to predict academic achievement at post-secondary levels.

O'Conner and Paunonen (2007) and others (Poropat 2009) have recommended that the Big Five personality factors be used to predict academic achievement in post-secondary education. O'Conner and Paunonen summarized the research across 23 studies and reported an average correlation of $r=0.24$ between conscientiousness and academic achievement. Similarly, Poropat (2009) conducted a meta-analysis and reported an average correlation of $r=0.22$ between conscientiousness and academic achievement. Additional studies have shown that the Big Five have predicted academic achievement, even after controlling for intelligence. For example, conscientiousness accounted for an additional $10 \%$ of the variance in GPA in a sample of Italian High School students (Di Fabio and Busoni 2007); conscientiousness and extroversion explained an additional $17 \%$ of the variance in academic achievement in a sample of young adolescents in Croatia (Bratko et al. 2006); and 
conscientiousness, extroversion, and openness to experience accounted for an additional $12 \%$ of the variance in grades on two statistics examinations at the university level (Furnham and Chamorro-Premuzic 2004).

Whereas the Big Five factors have predicted academic achievement, the use of more narrow personality measures has also been recommended by O'Conner and Paunonen. For example, conscientiousness can be subdivided into the facets of competence, deliberation, dutifulness, order, achievement striving, and self-discipline - and the latter two have been particularly good at predicting academic achievement. Achievement striving involves being ambitious, diligent, and persistent whereas self-discipline involves the motivation to finish tasks and resist distractions. Reported correlations for these two facets have ranged from $r=$ 0.15 to $r=0.39$ for achievement striving, and from $r=0.18$ to $r=0.46$ for self-discipline (O'Conner and Paunonen 2007). Openness to Experience can be subdivided into ideas, fantasy, and aesthetics, however empirical evidence with academic achievement is mixed. Studies report modest correlations, mostly negative, but in some cases positive. Similarly, mixed results have been reported for the facets of extroversion. The facets for neuroticism include impulsivity and anxiety and Chamorro-Premuzic and Furnham (2003) have reported negative correlations with GPA for impulsivity $(r=-0.26)$ and for anxiety $(r=-0.29)$. No significant relations between the facets of agreeableness and GPA have been reported. Additional recommended personality measures include achievement, dominance, exhibition, defendence, abasement, nurturance, play, understanding, organization, risk-taking, interpersonal warmth, conformity, and anxiety.

Thirdly, O'Conner and Paunonen (2007) suggested that the effects of intelligence and personality would depend on how academic achievement was operationalised and therefore recommended that multiple measures of academic achievement be used. They cited work by Rothstein et al. (1994) who compared the effects of intelligence and personality on academic achievement and reported that written performance was more strongly predicted by intelligence whereas classroom participation was more strongly predicted by personality - specifically extroversion. That there has been a consistent lack of variety in how academic achievement has been measured in post-secondary studies is evident from the research reviewed by O'Conner and Paunonen. They listed 23 published studies between 1991 and 2006 and reported how each study had measured academic achievement: GPA (16 studies), exam grade (6), essay grade (2), written performance (1), thesis research (1), and classroom participation (1).

Although the use of diverse, multiple measures of academic achievement has been scarce, a recent study by Kappe and van der Flier (2010) assessed the predictive utility of the Big Five for multiple criteria of academic achievement. In addition to performance on exams, the authors measured curriculum-appropriate skills acquisition, team work on group projects, written and oral performance on a thesis, and performance during a student internship. They reported that conscientiousness was an important predictor of academic achievement regardless of how it was measured, and that neuroticism was positively related to achievement when the assessment conditions were less stressful. However, they did not measure intelligence, nor narrow measures of personality, nor motivation, and they reported only bivariate statistics.

A final recommendation by O'Conner and Paunonen (2007) was to examine the direct predictive utility of each predictor, as well as its incremental validity, in a multivariate context. They noted that conclusions concerning the relations between personality and achievement have often been drawn exclusively on the basis of zero-order predictorcriterion relations (O'Conner and Paunonen 2007). Such zero-order correlations are useful for determining an initial link but should be followed by examining the unique or 
incremental validity of each personality variable in relation to other variables such as motivation and cognitive ability. Based on the literature review above, the following hypotheses were formulated:

Hypothesis 1: Personality variables explain additional variance in academic achievement over and above intelligence.

Hypothesis 2: Conscientiousness explains additional variance across a wide range of academic achievement measures over and above intelligence.

In summary, this study answered the call from O'Conner and Paunonen (2007) to use multiple predictors and criteria, narrow measures of personality in addition to Big Five factors, and to combine the results in a multivariate context. And, whereas the majority of research in this area has been conducted in English speaking countries, the current study was conducted in The Netherlands, which would, in the event of significant findings, add to the robustness of research concerning how well intelligence and personality factors predict academic achievement.

\section{Method}

Sample

Undergraduate human resource management (HRM) students in a post-secondary, professional school of higher educational learning participated in the research. Students studied such issues as how to reintegrate the long term unemployed into the workforce, or help employees plan their careers, as well as the legal steps involved in employee termination. The current program used a variety of learning environments such as classroom tuition, group projects, and skills training, which promoted competence-based learning. A large amount of time was devoted to internship training in actual business settings during the second, third, and fourth years, and students were required to write a thesis during the last 6 months of their study.

Students had finished their secondary school education, had entered as first year freshmen, and were generally between 18 and 22 years old. The data came from four cohorts of students. Cohort 1 started their education in 2000 and cohorts 2, 3, and 4 started their educations in 2001, 2002, and 2003, respectively. The entire sample, across all four cohorts, consisted of 174 students. However, 26 students dropped out prematurely and could not be included in the study because the predictor measures were collected at the end of the first year of the program. There were a total of 34 students in the 2000 cohort, of whom four dropped out prematurely; therefore, $88 \%$ of the enrolled students participated in the current study. Drop-out and participation figures for the other three cohorts were as follows: $9 / 79 \%$ for the 2001 cohort, $7 / 88 \%$ for the 2002 cohort, and $6 / 85 \%$ for the 2003 cohort. Of the 148 students who participated in the study, a further 11 students were not included because complete predictor and criterion data were unavailable. The distribution of gender favoured females (74\%) over males (26\%).

A power analysis with a two-tailed significance test, alpha $=0.05$, and $n=137$ yielded a value of 0.81 . An estimated effect size of $r=0.30$ was posited, which was based on a review of several studies that had reported incremental validities of the Big Five factors with academic achievement, above and beyond intelligence.

\section{Predictor measures}

Intelligence Student intelligence was measured with the short version of the Multiculturele Capaciteiten Test voor Hoger Niveau (MCT-H; Multicultural Test of Intellectual Ability for 
Higher Education) by Bleichrodt and Van den Berg (1999). This test was developed especially for students in higher education, is considered a psychometrically sound instrument by the Dutch Testing Committee, the COTAN (Evers et al. 2000), and is used widely in Dutch Higher Education. The COTAN assessed the MCT-H on the following criteria: construct and criterion validity, reliability, principles of test construction, quality of test material, norms, and quality of the manual. As an example of construct validity the correlations between gender and intelligence in this test are alike correlations reported in the manuals of other international intelligence tests. The correlation with age was also examined. Results show a negative correlation for fluid intelligence and a positive correlation for crystallized intelligence, both in line with international research. The following three subtests, listed with their corresponding reliabilities, were used: double-word analogies items such as, shoe is to $\ldots$ as glove is to $\ldots(\alpha=0.95)$, exclusion items in which two pictures, out of a series of six, were excluded $(\alpha=0.84)$, and speed and accuracy tests in which word or number pairs were compared $(\alpha=0.96)$. This shorter version of the MCT-H was used because of time constraints and to minimize test fatigue. The short version has a reliability of 0.91 and has been shown to correlate as high as $r=0.86$ with the long version, whose overall reliability is 0.97 .

Big Five personality All students completed the short version of the NEO, the NEO Fivefactor Inventory (NEO-FFI) (Costa and McCrae 1992). The NEO-FFI is composed of 60 self-descriptive statements; 12 statements for each of the five factors. Items were rated on a five point Likert scale, ranging from 1 (strongly disagree) to 5 (strongly agree). A reference to the Dutch language version can be found in Hoekstra et al. (1996). Cronbach alphas for the current study were as follows: conscientiousness $(0.84)$, neuroticism $(0.83)$, extroversion (0.77), agreeableness $(0.64)$, and openness to experience $(0.72)$. These values coincided closely with reliability values that have been reported in the NEO-FFI manual.

Items for the remaining personality variables of intrinsic motivation and anxiety were taken from the WerkStijlenVragenlijst (Questionnaire About One's Style of Working) by Akkerman and van der Linden (2000), which in turn was based on the work of Hermans (1967, 1976). Four additional variables: anxiety, need for status, motivation to study, and environmental press, were also taken from the WerkStijlenVragenlijst and were included in the current research on an exploratory basis. Items on all scales were rated on seven point Likert scales, ranging from 1 (strongly disagree) to 7 (strongly agree).

Intrinsic motivation The intrinsic motivation subscale consisted of 12 items. Sample items include: 'I feel that everything I do must be of a high standard', 'I often do more than is expected of me', and 'People should not put off until tomorrow that which can be done today'. The user manual has reported the following intercorrelations: extroversion $(0.27)$, neuroticism $(-0.27)$, and conscientiousness $(0.56)$. The internal reliability $(\alpha)$, as measured in the current study was 0.79 .

Anxiety Anxiety was defined as underachieving due to uncertainty and stress when tasks are experienced as difficult or must be performed under stressful conditions. Sample items include: 'I am the type of person who can develop interesting ideas, but who has difficulty acting upon them' and 'The thought that a decision might turn out wrong makes me freeze in my tracks'. The scale contained 27 items and registered an internal reliability $(\alpha)$ of 0.86 . A high score implied the experience of strong feelings of fear and stress. O'Conner and Paunonen listed anxiety as a variable of interest and studies have shown it to correlate -0.29 with school grades (Hembree 1988), -0.28 with oral 
exams (Diaz et al. 2001), and -0.29 with scholastic achievement (Chamorro-Premuzic and Furnham 2003). As might be expected, anxiety is also correlated with other predictors of academic achievement such as intelligence, $r=-0.33$ (Ackerman and Heggestad 1997), and neuroticism, $r=0.53$ (Busato et al. 2000).

Environmental press Environmental press was defined as the need for additional tension and challenging tasks to reach optimal performance. Sample items included: 'I work a lot better when under pressure', 'I am easily distracted when there is no pressure', and 'I only really get into gear as a deadline approaches'. The scale contained 13 items and registered an internal reliability $(\alpha)$ of 0.84 . A high score implies that additional pressure is needed to motivate an individual to perform.

Need for status The need-for-status was defined as an internal desire to define success by comparing oneself to others. It consisted of 15 items, such as: 'What others think of my accomplishments is important to me', 'I often compare my accomplishments to those of others', and 'I strive for positions in life that provide recognition'. The user manual reported the following correlations: extroversion $(0.33)$, agreeableness $(-0.39)$, and conscientiousness $(0.21)$. The internal reliability $(\alpha)$, as measured in the current study was 0.86 .

Motivation to study Motivation to study was defined as the motivation to learn new knowledge and skills and the desire to study for one's personal development. Sample items for this 12 item scale included: 'I would rather read a textbook than watch a movie' and 'One needs a good education in order to advance in life'. The scale has shown the following intercorrelations: extroversion (0.27), neuroticism (0.26), conscientiousness $(0.46)$, openness to experience $(0.27)$, and intrinsic motivation $(0.52)$. The internal reliability $(\alpha)$ was 0.76 .

\section{Measures of academic achievement}

Grades on five different measures of academic achievement were obtained for each student: classroom lectures, skills training, group projects, internship training, and written thesis. Students were graded by their teachers on a scale from 1 to 10 , with 6 representing a pass, for each completed course or learning module. Lecture, skills training, team project, and internship training grades were collected throughout the curriculum, and the thesis was graded at the end of the curriculum. Cumulative GPA was included as an overall measure of academic achievement as was time-to-graduation.

Lectures Teachers graded students on multiple choice and essay exams and the grades reflected how well students had attended to classroom lectures and assigned textbook readings. In total, over the first 3 years of the HRM curriculum students had 25 lecture courses. Therefore, GPA lectures was based on 25 grades.

Skills training Students learned general skills such as negotiating and debating, as well as curriculum specific skills such as how to conduct an employment interview. Teachers used theoretical presentations, acting, role playing, and videos to help students master the skills and considerable social interaction was required between the students and the teacher. Students wrote short reports after class (e.g. at home) in which they reflected on their training experiences and these reports were graded by the teacher. In total, students were graded on ten different training courses during the 4-year HRM curriculum. 
Team projects Students worked in teams of five over a 10-week period and developed HRM programs (e.g. selection and training) or products such as an HRM handbook or a Health \& Safety manual. Students planned their own projects and the teamwork required students to learn how to communicate, plan, and resolve conflicts with one another. The project was scored as a whole; therefore, students were dependent on each others' contribution and performance. Whereas first year students were assigned to project teams, students chose with whom they wanted to work in all subsequent years. Students were graded on ten different team projects during the 4-year HRM curriculum.

Internship training Students worked as junior employees in actual business settings in curriculum relevant areas such as recruiting and applying government employment regulations. Students were trained by experienced supervisors and grades were obtained after discussion between the workplace supervisor and the student's teacher. Students received 6 weeks of training during their second year, and 20 weeks during the third and fourth years.

Thesis Each student submitted a 30-page thesis towards the end of the curriculum in which practical business problems and solutions were discussed, often stemming from internship experiences. The student's supervisor, as well as an independent faculty member, rated the thesis and corresponding oral presentation, and agreed to final grades after discussion.

GPA GPA was the weighted, cumulative average of grades across all subject matter during the student's entire tenure at school.

Time to graduation Time-to graduation was the number of months required for a student to complete the curriculum and graduate from the program. The formal curriculum was meant to be completed in 4 years; however, the system was somewhat flexible and a number of students took longer to complete their studies.

\section{Results}

Bivariate correlations for all predictor and criterion variables, as well as descriptive statistics, have been listed in Table 1 . As is often reported intelligence was not significantly correlated with any of the personality variables. As expected in our sample of post-secondary students, intelligence showed only small correlations with measures of academic achievement. In contrast, conscientiousness showed large correlations with the five specific academic achievement criteria, GPA, and time-to-graduation. Intrinsic motivation was correlated with almost all of the criteria, however intrinsic motivation and conscientiousness were substantially intercorrelated $(r=0.45)$. Motivation to study was obviously relevant in a college level sample, and it correlated consistently with academic achievement; however, it correlated highly with intrinsic motivation $(r=0.62)$ and conscientiousness $(r=0.33)$ which shows that it too was not a purely independent construct. Anxiety was unrelated to any of the performance criteria, however it correlated as expected with neuroticism $(r=0.32)$. Need for status was unrelated to any of the academic achievement criteria, however environmental press showed small inverse correlations with a few of the criteria. The Big Five personality traits showed low intercorrelations amongst themselves, except for a rather high correlation between extroversion and neuroticism $(r=-0.41)$. Finally, the academic achievement criteria 


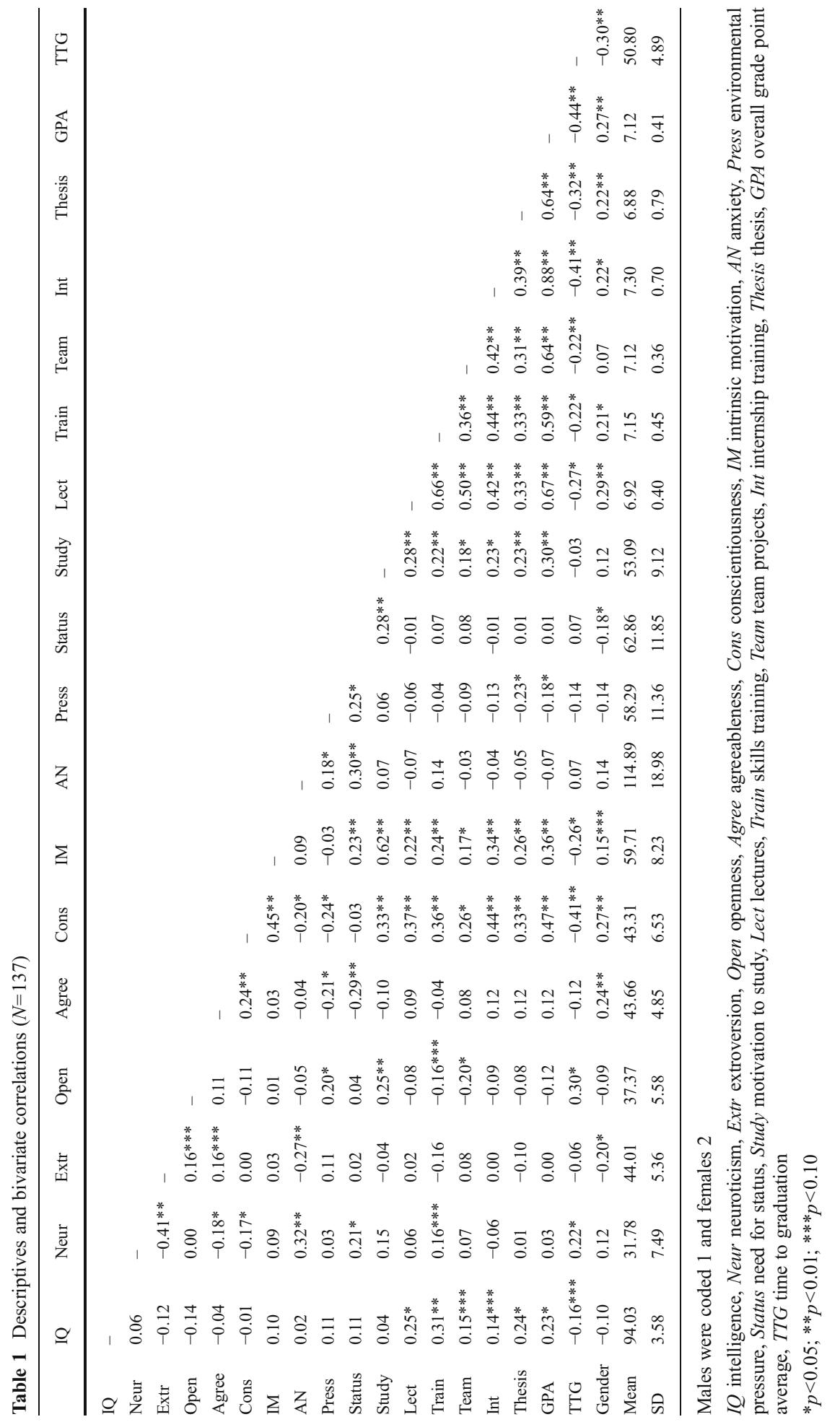


were consistently intercorrelated amongst themselves in the expected directions: good students did well consistently across a broad spectrum of academic criteria.

The first hypothesis stated that personality would explain additional variance in academic achievement over and above intelligence. This hypothesis was supported for GPA, time-tograduation, and for each of the five separate measures of academic achievement. The Big Five traits together registered incremental validities, over and above intelligence, of $\Delta R^{2}=$ 0.24 for GPA and $\Delta R^{2}=0.25$ for time to graduation. Intrinsic motivation registered incremental validities of $\Delta R^{2}=0.11$ for GPA and $\Delta R^{2}=0.06$ for time-to-graduation. The four narrow traits of anxiety, motivation to study, need for status, and environmental press together registered an incremental validity of $\Delta R^{2}=0.14$ for GPA, but no significant effect for time to graduation. The proportions of variance explained by intelligence were $R^{2}=0.05$ for GPA and $R^{2}=0.03$ for time to graduation.

The second hypothesis, which stated that conscientiousness will account for additional variance across a wide range of academic achievement measures over and above intelligence, was also supported. Conscientiousness showed the following incremental validities: GPA $\left(\Delta R^{2}=0.22\right)$, time to graduation $\left(\Delta R^{2}=0.17\right)$, lectures $\left(\Delta R^{2}=\right.$ $0.14)$, skills training $\left(\Delta R^{2}=0.13\right)$, team projects $\left(\Delta R^{2}=0.07\right)$, internship training $\left(\Delta R^{2}=\right.$ $0.19)$, and thesis $\left(\Delta R^{2}=0.11\right)$.

We further examined the predictive value of the total set of predictor variables and examined their unique contribution in relationship to each other for GPA, TTG and the five specific measures of academic achievement. The results are listed in Table 2. Results show that $33 \%$ of the variance in GPA and $30 \%$ of the variance in time to graduation can be explained by combining intelligence, personality, and motivational predictors. Conscientiousness was by far the most important predictor with significant and large beta values for all dependent variables. Therefore, hypothesis 2 is fully

Table 2 Results of multiple regression analyses for all variables

\begin{tabular}{|c|c|c|c|c|c|c|c|}
\hline & $\begin{array}{l}\text { GPA } \\
\beta\end{array}$ & TTG & $\begin{array}{l}\text { Lectures } \\
\beta\end{array}$ & $\begin{array}{l}\text { Skills } \\
\text { training } \\
\beta\end{array}$ & $\begin{array}{l}\text { Team } \\
\text { projects } \\
\beta\end{array}$ & $\begin{array}{l}\text { Internship } \\
\text { training } \\
\beta\end{array}$ & $\begin{array}{l}\text { Thesis } \\
\beta\end{array}$ \\
\hline Intelligence & $0.23 * *$ & $-0.14 * * *$ & $0.26^{* *}$ & $0.30 * *$ & 0.13 & $0.14 * * *$ & $0.25^{* *}$ \\
\hline Neuroticism & 0.10 & $0.15 * * *$ & $0.15^{* * *}$ & $0.15^{* * *}$ & $0.17 * * *$ & -0.01 & -0.01 \\
\hline Extroversion & 0.09 & -0.06 & 0.14 & 0.02 & $0.20 *$ & 0.03 & -0.05 \\
\hline Openness & -0.08 & $0.22 *$ & -0.09 & -0.07 & $-0.25 *$ & -0.03 & -0.02 \\
\hline Agreeableness & 0.04 & -0.01 & 0.03 & -0.11 & 0.09 & 0.02 & 0.07 \\
\hline Conscientiousness & $0.37 * *$ & $-0.32 * *$ & $0.34 * *$ & $0.44 * *$ & $0.20 * * *$ & $0.34 * *$ & $0.19 * * *$ \\
\hline Intrinsic motivation & 0.06 & $-0.19 * * *$ & -0.11 & -0.05 & -0.10 & 0.16 & 0.05 \\
\hline Anxiety & 0.01 & -0.06 & 0.00 & $0.20 *$ & -0.02 & 0.04 & 0.00 \\
\hline Need for pressure & -0.10 & 0.02 & 0.00 & -0.01 & -0.03 & -0.05 & $-0.20^{*}$ \\
\hline Need for status & -0.05 & 0.06 & -0.10 & -0.08 & 0.05 & -0.06 & 0.02 \\
\hline Study motivation & 0.16 & 0.11 & $0.26^{*}$ & 0.08 & $0.21 * * *$ & 0.04 & 0.15 \\
\hline$R^{2}$ & 0.33 & 0.30 & 0.26 & 0.31 & 0.19 & 0.24 & 0.23 \\
\hline$F(11,125)$ & $5.61 * *$ & $4.95 * *$ & $3.93 * *$ & $5.15 * *$ & $2.58 * *$ & $3.62 * *$ & $3.40 * *$ \\
\hline Adjusted $R^{2}$ & 0.27 & 0.24 & 0.19 & 0.25 & 0.11 & 0.18 & 0.16 \\
\hline
\end{tabular}

GPA overall grade point average, TTG time to graduation

${ }^{*} p<0.05 ; * * p<0.01 ; * * * p<0.10$ 
supported. Intelligence was the second predictor of importance with significant beta values for GPA, lectures, skills training and thesis.

We also investigated whether gender would account for variance in the dependent measures above and beyond intelligence, personality, and motivation. The females had higher GPAs $(r=0.27)$, graduated faster $(r=-0.30)$, were more conscientious $(r=0.27)$, more agreeable $(r=0.24)$, although less extroverted $(r=-0.20)$, and showed less need for status $(r=-0.18)$. Results showed that gender accounted for an additional $2 \%$ of the variance in GPA and an additional $5 \%$ in time to graduation. The effects of other predictor variables in the equation remained stable when gender was added. Differential validity - that is whether intelligence, personality, and motivation predicted academic achievement differently for males than for females-was also investigated. Multivariate analyses for GPA and time to graduation, in which gender functioned as a fixed factor and intelligence and personality functioned as covariates, revealed no significant interaction effects.

Finally, as recommended by O'Conner and Paunonen (2007) we used structural equation modelling (SEM). We used the observed predictor and criterion data of the 137 participants and entered the data as manifest variables. Based on theory, we included the following predictor variables in the SEM analysis: intelligence, conscientiousness, intrinsic motivation and study motivation. We tested this theoretical model in which these predictors were included for GPA as well as for time to graduation. The model with all variables totalling eight possible paths showed a perfect fit, however some of the paths were nonsignificant. We deleted the path with the smallest $t$ value and subsequently retested the model. In the first analysis, we deleted the path between intrinsic motivation and GPA, in the second analysis the path between intrinsic motivation and time to graduation, and in the third analysis the path between study motivation and GPA. The final model with only significant paths $(t$ values $>2.0)$ is shown in Fig. $1\left(\chi^{2}=2.63 ; d f=1 ; p=0.10\right.$, RMSEA=1.35). Significant paths were found between conscientiousness and intelligence for both GPA and time to graduation and between study motivation and GPA. This analysis shows that in combination with conscientiousness study motivation is more important than intrinsic motivation. This latter is explained by the contextual specificity of study motivation in comparison with intrinsic motivation.

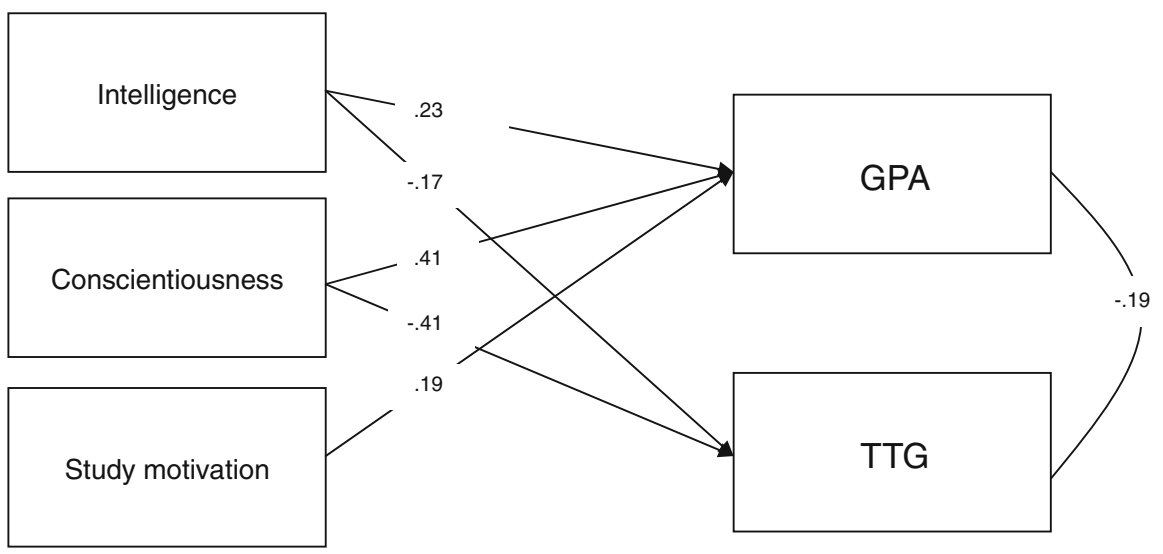

Fig. 1 Path diagram 


\section{Discussion}

The data show clearly that a combination of variables can accurately predict academic achievement. In fact, $33 \%$ of the variance in GPA and $30 \%$ of the variance in time to graduation can be explained by combining intelligence, personality, and motivational predictors.

The findings in this study support the writings of Harris (1940), Cattell (1965), and O'Conner and Paunonen (2007) that personality is an important predictor of academic achievement in post-secondary education. Intelligence, when entered as the first variable in the regression equation, accounts for only $5 \%$ of the variance in GPA in the current study, which coincides with the 4\% reported by Farsides and Woodfield (2003) and 3\% reported by Furnham and Chamorro-Premuzic (2004).

Conscientiousness is the most consistent and strongest predictor of academic achievement. Not only does conscientiousness, after controlling for intelligence, account for $22 \%$ of the variance in GPA and $17 \%$ of the variance in time-to-graduation, it is also consistently related to each of the five specific performance criteria. The current findings dovetail nicely with those of Mount et al. (1998) who report that conscientiousness correlates with various job related performance criteria across diverse occupations. Conscientious individuals perform better because they persevere longer and are more organized than their counterparts.

Intrinsic motivation is related to both GPA and time-to-graduation and by itself explains almost twice as much variance in GPA as does intelligence. The magnitude of the effect of intrinsic motivation coincides with the meta-analytic mean population correlation of 0.26 reported by Robbins et al. (2004) and of 0.24 found by Vallerand et al. (1993) in a comparable sample of 220 undergraduate college students. Intrinsic motivation also correlates significantly with four of the five specific academic achievement criteria in this study. However, a caveat is in order in that intrinsic motivation, conscientiousness and study motivation are strongly related. Whereas the bivariate correlations between intrinsic motivation and the achievement measures are sizeable, the partial correlations after controlling for conscientiousness are much smaller. A simple reason for this finding is that a number of items between the two scales of conscientiousness and intrinsic motivation have quite similar content. In the following examples, the first item is from the conscientiousness scale, whereas the second item is from the intrinsic motivation scale: (a) 'I am a productive person who always finishes what I start/I always finish whatever I start'. (b) 'I am quite good at motivating myself to finish things on time'/'People should not put off until tomorrow that which can be done today'. (c) 'I work hard to reach my goals'/'I keep working until a problem is solved'. In all, seven items between the two scales have highly similar meaning, which is considerable because both scales have only 12 items. A factor analysis ${ }^{1}$ of the conscientiousness and intrinsic motivation items yields a three factor solution. The factor analysis shows that the mentioned item pairs load on the same factor. Clearly, components of conscientiousness and intrinsic motivation are similar. Therefore, adding motivational factors in a prediction model with personality traits can lead to the inaccurate perception that motivation is less important.

Although not all findings need to be replicated across cultures, it is advisable to do so when cultural contingencies raise doubts about whether findings from important initial studies are generalizable. Dutch higher education practices differ from those in other countries in three notable ways. Admission standards are much less stringent. Students who complete their high school education are automatically admitted to an institute for

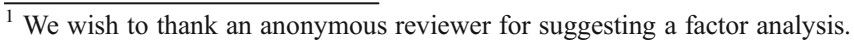


higher education and selection criteria such as high school GPA, SAT, or ACT scores are not generally used. Second, higher education in The Netherlands is substantially subsidized by the government and is therefore much less of a financial burden on students and their families. Therefore, there is presumably less external pressure on students to succeed. Yet, even in this context, the effect of conscientiousness on academic achievement is still quite large. Third, the curriculum of the HRM program in this study is quite fixed in the sense that all students follow the same courses, which is different from a typical university liberal arts curriculum in which students have more flexibility after having chosen a major.

Although a strength of the current study is the realism and face validity of the context, a limitation is that it is necessary to work with the measures at hand, namely those used by the school of higher education that participated in this research. Thus, one clear limitation in this study is that the narrow personality factors such as need-for-status and environmental press are not, as is recommended by O'Conner and Paunonen, among the type of 30 narrow facets of Big Five factors that are measured by the NEO-PI-R (Costa and McCrae 1992). It is unclear why anxiety, which is mentioned as one of the 30 facets, did not correlate appreciably with the achievement criteria. This may be related to how anxiety is operationalized, or to the sample being Dutch. Additional research is needed concerning the degree to which narrow personality measures account for variance in academic achievement above and beyond the Big Five factors (O'Conner and Paunonen 2007). A second limitation concerns the $15 \%$ of the enrolled students who did not finish the program. This is however a natural occurrence in higher education and might make the conclusions more conservative. Had the drop-outs been included it is possible that they would have scored lower on conscientiousness as well as had lower GPAs. A third limitation is that there is no measure of class attendance or self-regulation in the current study, variables which account for significant variance in GPA beyond intelligence (Farsides and Woodfield 2003). Finally, it should be noted that although the measure of intelligence used in this study is endorsed by experts in psychometrics, is widely used in The Netherlands, and shows some evidence of construct validity, there is no convergent validity data of this test with more commonly used IQ tests.

The results of this study have practical utility for admission boards and counsellors. Students who are intelligent and conscientious, and who therefore do not need additional pressure to study, can participate in a special honours program in which they are challenged more during their coursework and for which they receive an additional commendation on their diploma that distinguishes it from a normal diploma. The diploma with commendation should give such students an edge when soliciting for employment. Conversely, students who score low on conscientiousness might benefit from programs that improve motivation, such as participating in study groups. A study group consists of several students who happen to be taking the same course and can be either self-supporting or coached by an advanced student who has already mastered the subject. The groups meet frequently, for example after lectures, and students share notes and discuss the subject in order to clarify difficult concepts. Students who are low in conscientiousness may also benefit from programs that provide more structure. This is especially important in the first year of college because a number of students experience difficulties when transitioning from secondary to higher education. Schools might consider a curriculum that has more deadlines, shorter assignments, more group assignments, clearly defined learning goals, and less second chances for passing examinations. Students will not need to plan as much when structure is provided and should therefore achieve better grades, finish their first year on time, and have lower dropout rates.

The practical utility of the time-to-graduation criterion is of interest to policy makers because education is costly. Post-secondary education in the Netherlands is almost entirely 
subsidized by the government, and both students and schools receive financial support from the government. The normal duration of a college education is 4 years; however, students may receive funding for one additional year to complete their studies if needed. Students who drop out must return their financial support to the government. Schools receive funding from the government for every student they graduate, commonly referred to as a 'diploma bonus'. Thus, students who fail to graduate become expensive liabilities, both to themselves as well as to their schools. Because conscientiousness, neuroticism, and openness to experience are related to time-to-graduation, students might be identified on these characteristics. Several post-secondary schools in the Netherlands are experimenting with screening students before they embark on their studies and use personality tests to assess incoming freshmen in an effort to increase graduation rates.

Harris noted in 1940 that 'ability and effort are two essential factors for student achievement' (Harris 1940, p. 151). At the post-secondary level of education, the findings of the current study show clearly that effort, especially in the form of conscientiousness, overshadows ability as a predictor of grades and of how quickly a student will graduate. More important than what a student can do, is what a student is willing to do.

Acknowledgements The authors acknowledge the reviewers and Dr. Wiersma for their helpful suggestions on improving the article.

Open Access This article is distributed under the terms of the Creative Commons Attribution Noncommercial License which permits any noncommercial use, distribution, and reproduction in any medium, provided the original author(s) and source are credited.

\section{References}

Ackerman, P. L., \& Heggestad, E. D. (1997). Intelligence, personality, and interests: evidence for overlapping traits. Psychological Bulletin, 121, 219-245.

Akkerman, A. E., \& van der Linden, M. C. (2000). Handleiding WerkStijlenVragenlijst [Manual: Questionnaire About How One Works]. Leiden: Pits.

Bleichrodt, N., \& van den Berg, R. H. (1999). Handleiding MCT-H [Manual: MCT-H]. Amsterdam: NOA/VU.

Boekaerts, M. (1995). The interface between intelligence and personality as determinants of classroom learning. In D. H. Saklofske \& M. Zeidner (Eds.), Handbook of Personality and Intelligence (pp. 161183). New York: Plenum.

Bratko, D., Chamorro-Premuzic, T., \& Saks, Z. (2006). Personality and school performance: incremental validity of self- and peer-ratings over intelligence. Personality and Individual Differences, 41, 131-142.

Busato, V. V., Prins, F. J., Elshout, J. J., \& Hamaker, C. (2000). Intellectual ability, learning style, personality, achievement motivation and academic success of psychology students in higher education. Personality and Individual Differences, 29, 1057-1068.

Cattell, R. B. (1965). The scientific analysis of personality. Harmondsworth: Penguin.

Chamorro-Premuzic, T., \& Furnham, A. (2003). Personality traits and academic examination performance. European Journal of Personality, 17, 237-250.

Chamorro-Premuzic, T., \& Furnham, A. (2005). Personality and intellectual competence. Mahwah, NJ: Lawrence Erlbaum.

Conard, M. A. (2006). Aptitude is not enough: how personality and behaviour predict academic performance. Journal of Research in Personality, 40, 339-346.

Costa, P., \& McCrae, R. (1992). Revised NEO Personality Inventory (NEO-PI-R) and NEO Five-factor Inventory (NEO-FFI): professional manual. Odessa: Psychological Assessment Resources Inc.

Di Fabio, A., \& Busoni, L. (2007). Fluid intelligence, personality traits and scholastic success: empirical evidence in a sample of Italian high school students. Personality and Individual Differences, 43, 2095-2104.

Diaz, R. J., Glass, C. R., Arnkoff, D. B., \& Tanofsky-Kraff, M. (2001). Cognition, anxiety, and prediction of performance in 1st-year law students. Journal of Educational Psychology, 93, 420-429.

Evers, A., van Vliet-Mulder, J. C., \& Groot, C. (2000). Documentatie van test en test research in Nederland 2000 [Documentation of tests and research on tests in the Netherlands 2000]. Assen: Van Grocum. 
Farsides, T., \& Woodfield, R. (2003). Individual differences and undergraduate academic success: the roles of personality, intelligence, and application. Personality and Individual Differences, 34, 1225-1243.

Furnham, A., \& Chamorro-Premuzic, T. (2004). Personality and intelligence as predictors of statistics examination grades. Personality and Individual Differences, 37, 1013-1022.

Furnham, A., Chamorro-Premuzic, T., \& McDougall, F. (2003). Personality, cognitive ability, and beliefs about intelligence as predictors of academic performance. Learning and Individual Differences, 14, 47-64.

Gilles, P. Y., \& Bailleux, C. (2001). Personality traits and abilities as predictors of academic achievement. European Journal of Psychology of Education, 16, 3-15.

Harris, D. (1940). Factors affecting college grades: a review of the literature, 1930-1937. Psychological Bulletin, 37, 125-166.

Hembree, R. (1988). Correlates, causes, and treatment of test anxiety. Review of Educational Research, 58, 47-77.

Hermans, H.J.M. (1967). Motivatie en prestatie [Motivation and Achievement]. Dissertation, University of Nijmegen. Amsterdam: Swets \& Zeitlinger

Hermans, H. J. M. (1976). Handleiding bij de Prestatie Motivatie Test (PMT) [Manual Achievement Motivation Test]. Amsterdam: Swets \& Zeitlinger.

Hoekstra, H. A., Ormel, J., \& de Fruyt, F. (1996). Handleiding NEO persoonlijkheids-vragenlijsten NEO-PI-R en NEO-FFI [Manual NEO-PI-R en NEO-FFI]. Lisse: Swets Test Services.

Kappe, F. R., \& van der Flier, H. (2010). Using multiple and specific criteria to assess the predictive validity of the Big Five personality factors on academic achievement. Journal of Research in Personality, 44, 142-145.

Mount, M. K., Barrick, M. R., \& Stewart, G. L. (1998). Five-factor model of personality and performance in jobs involving interpersonal interactions. Human performance, 11, 145-165.

Noftle, E., \& Robins, R. (2007). Personality predictors of academic outcomes: Big Five correlates of GPA and SAT scores. Journal of Personality and Social Psychology, 93, 116-130.

O'Conner, M. C., \& Paunonen, S. V. (2007). Big Five personality predictors of post-secondary academic performance. Personality and Individual Differences, 43, 971-990.

Petrides, K. V., Chamorro-Premuzic, T., Frederickson, N., \& Furnham, A. (2005). Explaining individual differences in scholastic behavior and achievement. British Journal of Educational Psychology, 17, 239-255.

Poropat, A. E. (2009). A meta-analysis of the Five-Factor model of personality and academic performance. Psychological Bulletin, 2, 322-338.

Resing, W. C. M., \& Drenth, P. J. D. (2007). Intelligentie: weten en meten: 2e, herziene druk [Intelligence]. Amsterdam: Uitgeverij Nieuwezijds.

Robbins, S. B., Lauver, K., Le, H., Davis, D., Langley, R., \& Carlstrom, A. (2004). Do psychosocial and study skill factors predict college outcomes? A meta-analysis. Psychological Bulletin, 130, 271-288.

Rothstein, M., Paunonen, S., Rush, J., \& King, G. (1994). Personality and cognitive ability predictors of performance in graduate business school. Journal of Educational Psychology, 86, 516-530.

Vallerand, R. J., Pelletier, L. G., Blais, M. R., Briere, N. M., Senecal, C., \& Vallieres, E. F. (1993). On the assessment of intrinsic, extrinsic, and a motivation in education: evidence on the concurrent and construct validity of the academic motivation scale. Educational and Psychological Measurement, 53, 159-172.

Rutger Kappe. Faculty of Psychology and Education, VU University Amsterdam, Van der Boechorststraat 1, 1081 Amsterdam, The Netherlands. E-mail: Rutger.Kappe@inholland.nl, E-mail: fr.kappe@psy.vu.nl

Current themes of research:

Educational researcher. Advisor and trainer at the office of Education, Quality, Research \& Development. Peer-, intake-, formative- and summative assessment. Quality issues in assessment. Learning and instruction. Foremost student success.

Most relevant publications in the field of Psychology of Education:

Kappe, F. R., \& Van der Flier, H. (2011). The predictive validity of academic assessment centers for career success: using uncontaminated criteria. Manuscript submitted for publication.

Kappe, F. R. (2011). Determinants of success: a longitudinal study in higher professional education. Doctoral dissertation. Amsterdam: VU University.

Kappe, F. R., \& Van der Flier, H. (2010). Using multiple and specific criteria to assess the predictive validity of the Big Five personality factors on academic achievement. Journal of Research in Personality, 44, 142-145. 
Kappe, F. R., Boekholt, L., Den Rooyen, C., \& Van der Flier, H. (2009). A predictive validity study of the Learning Style Questionnaire (LSQ) using multiple, specific learning criteria. Learning and Individual Differences, 19, 464-467.

Henk van der Flier. Faculty of Psychology and Education, VU University Amsterdam, Van der Boechorststraat 1, 1081 Amsterdam, The Netherlands

Current themes of research:

Professor emeritus in Work and Organizational Psychology at the VU University. Working Conditions, Safety, Personnel Selection, Psychometrics (Person Fit, Item Bias) and Cross-Cultural Psychology. Educational Selection in developing countries and the use of selection tests for immigrant groups in the Netherlands.

Most relevant publications in the field of Psychology of Education:

Kappe, F. R., \& Van der Flier, H. (2011). The predictive validity of academic assessment centers for career success: using uncontaminated criteria. Manuscript submitted for publication.

Kappe, F. R., \& Van der Flier, H. (2010). Using multiple and specific criteria to assess the predictive validity of the Big Five personality factors on academic achievement. Journal of Research in Personality, 44, $142-145$.

Kappe, F. R., Boekholt, L., Den Rooyen, C., \& Van der Flier, H. (2009). A predictive validity study of the Learning Style Questionnaire (LSQ) using multiple, specific learning criteria. Learning and Individual Differences, 19, 464-467.

Maij - de Meij, A. M., Kelderman, H., \& Van der Flier, H. (2010). Improvement in detection of differential item functioning using a mixture item response theory model. Multivariate Behavioral Research, 45, 975999.

Van der Flier, H., Thijs, G. D., \& Zaaiman, H. (2003). Selecting students for a South African mathematics and science foundation program: effectiveness and fairness of school-leaving examinations and aptitude tests. International Journal of Educational Development, 23, 399-409.

Nijenhuis, J. te, \& Van der Flier, H. (1997). Comparability of GATB scores for immigrants and majority group members: some Dutch findings. Journal of Applied Psychology, 82, 675-687.

Van der Flier, H. (1982). Deviant response patterns and comparability of test scores. Journal of Cross-Cultural Psychology, 13, 267-298. 